University of Wollongong

Research Online

Faculty of Informatics - Papers (Archive)

Faculty of Engineering and Information

Sciences

$1-10-2003$

\title{
The reporting of distribution power quality surveys
}

V. J. Gosbell

University of Wollongong, vgosbell@uow.edu.au

Alex Baitch

University of Wollongong, abaitch@uow.edu.au

M. H. Bollen

Chalmers University of Technology, Sweden

Follow this and additional works at: https://ro.uow.edu.au/infopapers

Part of the Physical Sciences and Mathematics Commons

\section{Recommended Citation}

Gosbell, V. J.; Baitch, Alex; and Bollen, M. H.: The reporting of distribution power quality surveys 2003. https://ro.uow.edu.au/infopapers/142

Research Online is the open access institutional repository for the University of Wollongong. For further information contact the UOW Library: research-pubs@uow.edu.au 


\title{
The reporting of distribution power quality surveys
}

\begin{abstract}
Power quality surveys can contain a large amount of data for many sites and several utilities. A reporting format needs to be adopted which gives useful insights without sacrificing detail. It is recommended that a three level structure be adopted with site, network and utility component styles. The first of these is the presentation of the raw data in slightly abbreviated form while the second allows all sites in one network to be ranked according to severity of their power quality disturbances. Utility reporting allows comparison between the overall power quality performance of different utilities in benchmarking studies. Some new data analysis algorithms are proposed to show how the reporting styles should be implemented.

\section{Disciplines}

Physical Sciences and Mathematics

\section{Publication Details}

This article was originally published as: Gosbell, VJ, Baitch, A \& Bollen, MHJ, The reporting of distribution power quality surveys, CIGRE/IEEE PES International Symposium on Quality and Security of Electric Power Delivery Systems, 8-10 October 2003, 48-53. Copyright IEEE 2003.
\end{abstract}




\title{
The Reporting of Distribution Power Quality Surveys
}

\author{
Victor J. Gosbell, Member, IEEE, Alex Baitch, Senior Member, IEEE and
}

Mathias H. J. Bollen, Senior Member, IEEE

\begin{abstract}
Power Quality surveys can contain a large amount of data for many sites and several utilities. A reporting format needs to be adopted which gives useful insights without sacrificing detail. It is recommended that a three level structure be adopted with Site, Network and Utility component styles. The first of these is the presentation of the raw data in slightly abbreviated form while the second allows all sites in one network to be ranked according to severity of their Power Quality disturbances. Utility reporting allows comparison between the overall Power Quality performance of different utilities in benchmarking studies. Some new data analysis algorithms are proposed to show how the reporting styles should be implemented.
\end{abstract}

Index Terms-Data Structures, Electromagnetic Compatibility, Data processing, Measurements, Power Quality, Power System Monitoring, Voltage.

\section{INTRODUCTION}

$\mathrm{R}$ OUTINE monitoring of power quality is becoming more common in distribution systems. One reason for this is increased interest in power quality issues by network operators and industrial customers. In Australia and many other countries, another reason is that state and national regulators are becoming more proactive following the deregulation of the industry. This is a major influence in the development of system-wide power quality indices. Routine power quality monitoring of a selection of sites is seen as providing some evidence that utilities have an effective power quality management strategy in place.

The measurement of power quality is not straightforward. There are, for example, different approaches which can be used to measure harmonics and these affect the results which will be obtained, especially when the harmonic levels vary with time. It is important that there be consistency in measurement procedure so that utilities can be compared and best practice established. Standards such as IEEE 1159 [1], IEC 61000-4-7 [2] and IEC 61000-4-30 [3] are important for specifying a consistent set of procedures for obtaining measurement results such as $95 \%$ values of particular

This work was supported by Integral Energy

V.J. Gosbell is with the School of Electrical, Computer and Telecommunications Engineering, University of Wollongong, Wollongong NSW, Australia 2522 (e-mail: v.gosbell@uow.edu.au).

A. Baitch is with BES (Aust) Pty Ltd, Baulkham Hills, NSW Australia 2153 (e-mail: baitch@besaust.com.au) Sweden harmonics, and the retained voltage and duration of voltage sags.

Another issue requiring standardisation is reporting of a monitoring campaign, particularly where it involves many sites over a period of a year. Summary indices need to be chosen which do not mask important diagnostic details. Additional complications occur when it is desired to make useful comparisons between the monitoring results for several utilities. In Australia, where two of the authors have been involved with benchmark power quality monitoring comparisons, there are a total of 16 distribution companies. Comparisons are seen as useful for disturbances such as sags where accepted maximum desirable levels are yet to be established.

For reporting purposes, a classification of importance is of Variation and Event disturbances (sometimes called Continuous and Discrete disturbances).

- Variations: present in each cycle of the waveform, for example voltage level, unbalance, flicker, harmonics.

- Events: resulting from a short term incident, such as sags, swells, impulsive and oscillatory transients.

These require different approaches for data analysis and reporting. It is also necessary to give separate reports for $\mathrm{LV}$ and MV parts of a distribution system since there are significant differences in planning and construction practices and applicable standards.

\section{OVERALL REPORTING REQUIREMENTS}

Some of the questions which a power quality reporting style has to address are:-

(i) Which sites will need attention as soon as possible?

(ii) What is the likely cause of the high disturbance levels?

(iii) Which protection practices are effective in reducing sag activity?

(iv) How does one utility compare with other utilities regarding its voltage regulation practices?

(v) What is a suitable limiting value for sags based on a national survey?

Questions such as the above can be seen to be classified into one of three levels

(i) The detailed behavior of one site.

(ii) A comparison between different sites in the one network.

(iii) A comparison between different utilities. 
In order to meet these requirements, it is recommended that three reporting styles be developed corresponding to each level with the data reported at each level being a summary of the level below. The three levels are:-

- Site report: details of one disturbance at one site are needed for post-mortem and diagnostic purposes.

- Network report: simple indices are produced for each disturbance at a site so that the sites can be easily prioritized for remedial work.

- Utility report: simple indices are produced for each disturbance for the whole network so that one utility can be compared with another.

In practice, the division between these reporting approaches is not clear-cut. Nevertheless, this classification has been found to be useful in developing reporting procedures for Australian distribution companies.

\section{REPORTING STYLES}

\section{A. Site reporting}

The aim of site reporting is to give sufficient detail about one disturbance at a site that post-mortem investigation and remedial decisions can be made. Site reporting is significant different for Variations and Events. For Variation disturbances, levels are obtained continuously, whereas single event characteristics are obtained only for each event.

Variations: The time variation of three phases over a long period is difficult to interpret. Histograms are recommended as being easier to interpret. It 'is admitted that there may ultimately be a need for the detailed view of part of the time trend for a final resolution of a particular problem.

The cumulative frequency plot can be shown overlaying the histogram as given in numerous previous papers, for example[4], as shown in Fig. 1. It can also be useful to overlay the cumulative frequency plot for the whole utility or for all monitored sites where several utilities participate in a monitoring campaign.

Events: A scattergraph with a CBEMA/ITIC overlay shows the duration/retained voltage characterization of each individual event occurring in the monitoring period as can be seen in Fig. 2. Another overlay showing typical distribution system protection settings has been found useful in identifying sags which are not due to reflected faults and with normal recloser operation.

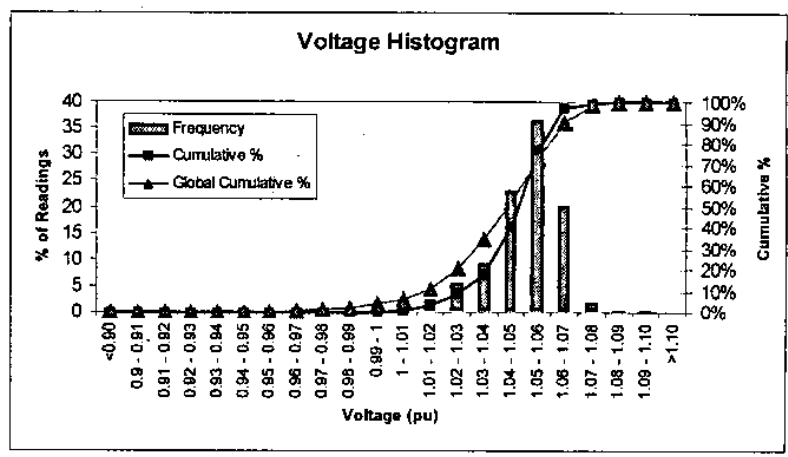

Fig. 1. Method for reporting voltage with,cumulative frequency overlay for both individual and all global readings

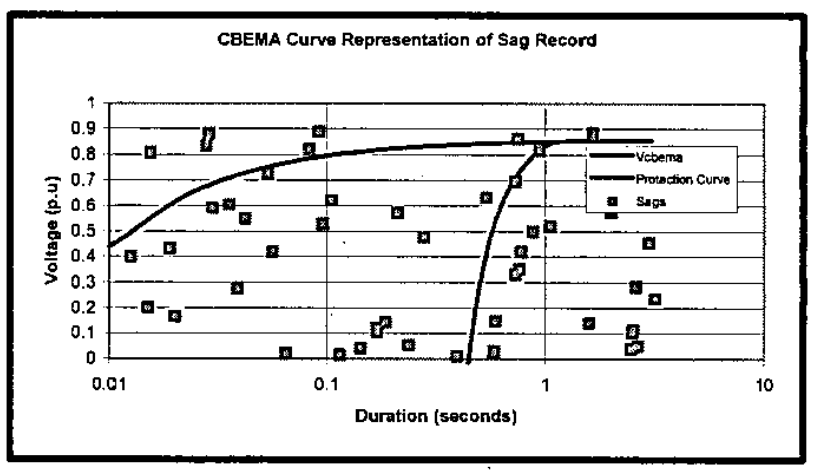

Fig. 2. CBEMA curve overlay for reporting sags

\section{B. Network reporting}

Network reporting aims to give simple site indices for all measurement points in the network so that sites can be prioritized for further investigation. Again the reporting is different for Variations and Events, with Variation site indices being a kind of average and Event site indices being a kind of event count. Different methods for obtaining site indices for voltage sags are discussed in IEEE Task Force P1564 and in CIGRE Working Group 36.07.

Variations: A single statistical index can be obtained for each phase over an agreed period, for example the $95 \%$ value of the 10 minute readings for one week. The three indices need to be aggregated across the three phases, a common practice being to take the worst value. The weekly values need to be aggregated across the survey period, for example by taking the maximum of the weekly values during one year. In the case of disturbances with several parameters such as flicker $\left(\mathbf{P}_{\mathrm{st}}\right.$ and $\left.\mathrm{P}_{\mathrm{lt}}\right)$ or distortion (THD and several harmonic values) it can be useful to combine these into a single flicker or distortion value as discussed in Section IV.B..

Events: A single index needs to be obtained for each disturbance type. One approach to achieving this is described in [5]. One first determines a severity index for each event. For sags, this might be based on a CBEMA number. The severity indices for all sites are summed to give a survey period disturbance index which is scaled to an agreed period such as one year to give a disturbance index. In principle this 
approach can be extended to swells and transients.

The result of the above is to determine single summary index corresponding to each disturbance type for each site. This can be presented as a table of indices for each type, ranked in an appropriate order. In the example shown in Table I for unbalance (VUF is Voltage Unbalance Factor), the $5 \%, 50 \%$ and $95 \%$ values for all monitored sites are also shown for benchmarking purposes.

Further insights can be obtained by a histogram of the site indices, giving the percentage of sites having different index ranges. This can be overlaid with the cumulative probability plot. Where there are several utilities, the cumulative probability plot for all sites in the survey can also be overlaid to provide a form of benchmarking - Fig. 3 shows an example using the Sag Index discussed in Section V.

TABLE I

SITES LISTED IN ORDER OF UNBALANCE

VUF Rank Order

\begin{tabular}{|c|c|c|}
\hline Site & $95 \%$ VUF & Ut Rank \\
\hline A7 & 2.331 & 1 \\
\hline Giobal 95\% & $2 \% 73$ & 12 \\
\hline A6 & 1.999 & 3 \\
\hline A14 & 1.778 & 4 \\
\hline A11 & 1.765 & 5 \\
\hline A2 & 1.311 & 6 \\
\hline A16 & 1.294 & 7 \\
\hline A1 & 1.210 & 8 \\
\hline A5 & 1.200 & 9 \\
\hline A13 & 0.871 & 10 \\
\hline A3 & 0.864 & 11 \\
\hline Globaf $50 \%$ & 0.864 & 611 \\
\hline A12 & 0.779 & 13 \\
\hline A4 & 0.759 & 14 \\
\hline A17 & 0.753 & 15 \\
\hline A8 & 0.729 & 16 \\
\hline A10 & 0.599 & 17 \\
\hline A18 & 0.575 & 18 \\
\hline A15 & 0.530 & 19 \\
\hline A19 & 0.508 & 20 \\
\hline Goba15\% & 0.339 & 21 \\
\hline A9 & 0.331 & 22 \\
\hline
\end{tabular}

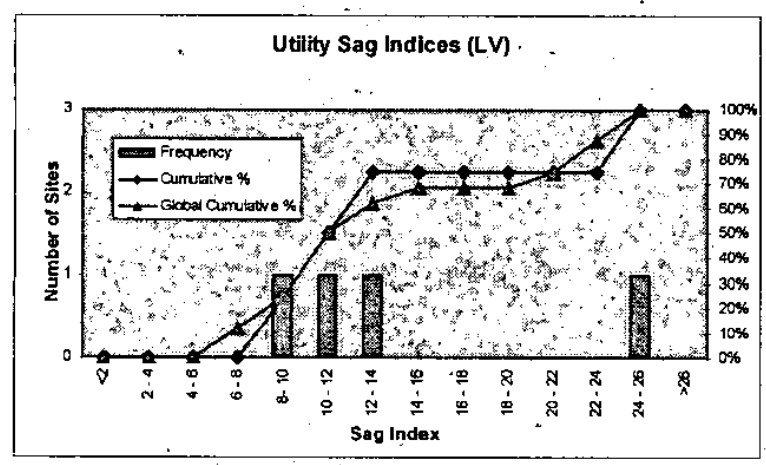

Fig. 3. Reporting of site index distribution

\section{Utility reporting}

Utility reporting aims to compare one utility with others so that site details of the other utilities are not revealed. There is little difference between the reporting of Variations or Events at the Network level. For each disturbance type, a single index can be obtained for the utility by combining the indices for all measured sites.

A utility can be compared with others by two methods, both of which are useful. Using a Voltage Index as a specific example

(i) The utility can compare its Voltage Index with the average of all utility Voltage Indices.

(ii) Utilities can be ranked by Voltage Index and each utility is given its rank.

The advantage of the first approach is that a utility can determine quantitatively how it performs relative to the global average. The second approach gives a rank for each disturbance type. This enables a single power quality indicator for a utility to be obtained by averaging the rank for each disturbance type. This approach accomplishes the difficult task of achieving a single indicator to represent the combined effect of voltage, harmonics, sags, etc, that is disturbances which are characterised in different ways with some having well-defined and others not so well-defined limits.

Another aim is to determine reasonable national power quality limits where standards are not yet developed or there is concern about straightforward adoption of international standards, possibly because of a difference in planning or construction practices. The following steps are recommended for each disturbance type

(i) Determine the $95 \%$ disturbance index value from all site indices. These are candidate values for national standard emission levels.

(ii) Determine the $95 \%$ disturbance index value from all monitored sites for a particular utility.

(iii) The ratio of (ii) to (i) is a measure of a utility's ability to meet the proposed standard, with smaller values being preferable.

\section{Data analysis triangle}

The above proposal results in each reporting style being derived from the data in the previous style. This leads to the data being considered in the form of a triangle as shown in Fig. 4 with each level being a summary of the information in the level below. Further details on the data structures and their relationships are given in [6].

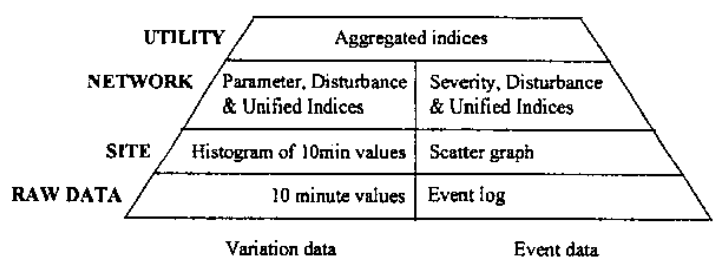

Fig. 4. Data analysis triangle

\section{SOME DETAILS OF VARIATION DISTURBANCE ANALYSIS}

\section{A. Voltage}

With the exception of voltage, all parameters such as voltage unbalance, flicker $\left(\mathrm{P}_{\mathrm{st}}\right)$, total harmonic distortion (THD), $5^{\text {th }}$ harmonic $\left(\mathrm{V}_{5}\right)$ etc should ideally be zero. The larger the value, the more unsatisfactory is the level of power 
quality disturbances. Thus a $95 \%$ value is a good indication of how bad a site is. Voltage is required to lie within a range and this needs special consideration. For Australian LV sites, the present range for line-neutral values is $230+10 \% /-2 \%$. MV sites have a desired range of voltage regulator float voltage \pm $3 \%$.

Voltage values need to be transformed into a value for which zero is the "best value". The Absolute Voltage Deviation (AVD), defined as the absolute difference between the measured voltage and the voltage in the middle of the desired range, is recommended. This can conveniently given as the percentage of the nominal voltage.

An example may make this clear. Suppose that a reading of $250 \mathrm{~V}$ is obtained for a nominal $230 \mathrm{~V}$ system.

- Nominal range is $225.4-253 \mathrm{~V}$.

- Middle of the nominal range is $239.2 \mathrm{~V}$.

- Absolute voltage deviation is $10.8 \mathrm{~V}$ or $4.7 \%$.

Appropriate limits for the $95 \%$ AVD are $6 \%$ at LV and $10 \%$ at MV. Note that this concept is equivalent to the voltage undertaking given in EN 50160 [7].

\section{B. Disturbance indices}

The process given in Section III.C naturally leads to one index for voltage (95\% AVD) and unbalance (95\% VUF), two for flicker ( $95 \%$ values for $\mathrm{P}_{\mathrm{st}}$ and $\mathrm{P}_{1 \mathrm{t}}$ ) and forty for harmonics (95\% values for THD and the harmonic magnitudes for $\mathrm{h}=2-40$ ). A single disturbance index can be found for flicker and harmonics by the two-step process of Normalisation and Consolidation [7].

- Normalisation: each parameter is divided by its limit value.

- Consolidation: The maximum of the normalised parameters is used.

For example, suppose the $\mathrm{P}_{\mathrm{st}}$ and $\mathrm{P}_{\mathrm{it}}$ limits are 0.9 and 0.7 respectively. A survey over 1 month gives $95 \%$ values for $P_{s t}$ and $P_{1 \mathrm{t}}$ of 0.81 and 0.6 respectively.

- Normalise: $\mathrm{P}_{\mathrm{st}}{ }^{\prime}=0.81 / 0.9=0.9, \mathrm{P}_{\mathrm{l}}{ }^{\prime}=0.6 / 0.7=0.86$.

- Consolidated flicker index $=\max (0.9,0.86)=0.9$.

\section{SOME DETAILS OF EVENT DISTURBANCE ANALYSIS}

Although event disturbances are very important, especially sags and impulsive transients, the methodology of reporting is not as well developed as for Variations. Transients in particular are poorly understood, probably because of difficulties in measurement and their rapid attenuation so that the importance of a particular transient depends strongly on the site position in the network relative to customer loads. The discussion in this section will concentrate on sags.

The analysis steps have been summarized in Section III.B. For sags, the raw parameters are sag voltage (retained voltage) and duration. Phase aggregation is the process of determining a single voltage and duration value for unbalanced sags. Time aggregation is the process of combining several closely spaced network events to give a single customer event. The timescale is about one minute and the most severe sags taken to characterize the event [5].

The concept of the sag severity index is developed in [6]. It is a single number for each event proportional to the number of customer problems that it would create. The concept is highly simplified since sites can supply very different types of customers having difference in their voltage tolerance.

It is assumed that the lines of constant sag severity are vertically scaled copies of the CBEMA curve. The main justification for this, in the absence of any detailed studies, is the widespread adoption of the CBEMA curve as a boundary between harmful and benign sags. Each contour is given a CBEMA number corresponding to the degree of scaling (based on an idea originated by Reliable Power Meters). The Sag Index is taken as the CBEMA Number of the curve passing through the sag with the following modifications

- Sags with retained voltages of $80-90 \%$ are given a reduced value to allow for uncertainty in power quality monitor threshold settings.

- The Sag Severity Index "saturates" at a CBEMA Number of 6.9 (passing through $0 \%$ voltage at 3 seconds). It is assumed that there will be no further increase in problems for more severe sags.

Site indices are obtained by adding the sag severity indices for all events that occurred at the site during the monitoring period. The resulting index is proportional to the average number of sag-related problems experienced by each customer. The result needs to be scaled up to an agreed survey period, typically a year, to allow comparison with other sites. In principle, a similar process can be followed for the other event disturbances.

\section{UTILITY INDICES}

Space aggregation is the process of combining disturbance indices across monitored sites to get an index for an area containing the sites. It can be applied to feeder indices to produce a substation index, or to substation indices to produce a district index. In particular, it can be applied to all sites in a utility to produce a utility index.

It is desirable that the aggregation process should possess the property of "scalability". This requires that the same index is calculated for a utility irrespective of the number of area indices used in the intermediate steps.

Suppose that we wish to obtain a utility index from two utilities having disturbance indices (for example Voltage indices) distributed as shown in Fig. 5. We suppose at first that each site serves the same MVA of load. The average of Utility A indices is 0.45 , smaller than the average value of 0.48 for Utility B. However, as far as customers are concerned, the large values which occur at two sites in Utility $A$ are not compensated for by the small values which occur at other sites. One would expect more satisfaction from Utility B's customers and this ought to be reflected in the lower value for a Utility index. This suggests that, in the determination of the overall utility index, large values should be weighted more than small ones. The RMS value has this property and Table II shows that the RMS value for Utility $B$ is indeed smaller than 
for Utility A.

Several variations on this proposal deserve consideration. It is possible to give a larger influence to the larger indices by choosing values greater than 2 for the exponent. This may be resolved by experience over time. If the MVA supplied by each site is known, and are very different in value, then the rms can be taken weighted by the appropriate MVA to emphasise the power quality experienced by most of the load demand. All of the possibilities described above meet the scalability criterion.

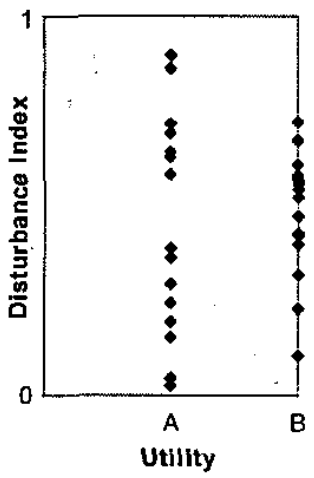

Fig. 5. Distribution of site indices for Utitities $A$ and $B$

TABLE II

UTILITY INDICES DETERMINED BY ALTERNATIVE METHODS

\begin{tabular}{|l|l|l|}
\hline Utility & Average Index & RMS Index \\
\hline A & 0.45 & 0.53 \\
\hline B & 0.48 & 0.50 \\
\hline
\end{tabular}

\section{SUMMARY}

Routine power quality survey measurements can be analysed to give useful insights into power quality levels in a utility. The reporting can be classified into Site; Network and Utility styles. Several data analysis procedures have been introduced to make the calculation of indices consistent and insightful.

For Network reporting, it is proposed that a single index be determined for each major disturbance type. Voltage is analyzed using the Absolute Voltage Deviation. The various indices for flicker and harmonics can be combined into one index for each disturbance type by the process of Normalisation and Consolidation. Sags can be represented by the sum of the individual Sag Severity Indices, scaled to an annual period.

Where the surveys cover several utilities, precautions need to be taken to present the results in such a manner that benchmark comparisons can be made without overriding confidentiality considerations. The paper has shown how this can be achieved by Utility reporting style. It is recommended that overall utility indices be determined by rms rather than the usual linear determination to favor utilities having a smaller spread of indices.

\section{REFERENCES}

[1] IEEE Recommended practice for monitoring electric power quality, IEEE Std 1159-1995, November 1995.

[2] General guide on harmonics and interharmonics measurements and instrumentation, for power supply systems and equipment connected thereto, IEC 61000-4-7:1991.

[3] Testing and measurement techniques - Power quality measurement methods, IEC-61000-4-30, final draft, Nov 2002.

[4] B.M. Hughes, J.S. Chan and D.O. Koval, "Distribution customer power quality experience", in IEEE. Trans on Industry Applications, vol. 29 no. 6., Nov/Dec 1993, pp. 1204-1211.

[5] V.J. Gosbell, D. Robinson and S. Perera, "The Analysis of Utility Voltage Sag Data", in Proc. International Power Quality Conference, Singapore, October 2002, pp. 479-490.

[6] V.J. Gosbell, B.S.P. Perera and H.M.S.C. Herath, "New framework for utility power quality (PQ) data analysis", in Proc AUPECOI, Perth, September 2001, pp. 577-582

[7] CENELEC EN 50160: "Voltage characteristics of electricity supplied by public distribution systems", CENELEC 1994

\section{BIOGRAPHIES}

Vic Gosbell (M'75): Dr Gosbell obtained his BE degree in 1966 and his PhD

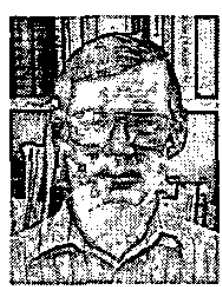
in 1971 from the University of Sydney. In 1973 he commenced lecturing at the University of Sydney and in 1990 took up a position of Associate Professor at the University of Wollongong where he is now the Professor of Power Engineering. His research interests are in power electronic simulation, harmonics and power quality. He is a Fellow of the Institution of Engineers, Australia and the immediate past Chaiperson of the Australasian Committee for Power Engineering

Alex Baitch (M'1984, SM'1993) is Principal of his own consulting practice

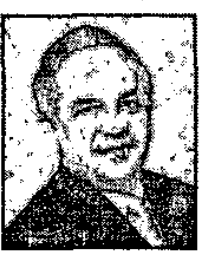
BES (Aust) Pty Ltd which he established in 1993. He obtained his BE degree in 1970 from the University of Sydney, MEngSc degree in 1974 and $\mathrm{MBA}(\mathrm{TechMgt})$ in 1995 . He has had a wide range of experience in the electrical industry, including close involvement with UPS systems and power quality issues. Alex has been closely involved in standards and professional activities.in Australia and internationally.

Math Bollen (M'94, SM'96) is professor in electric power systems at

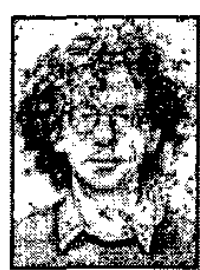
Chalmers University of Technology. He received his $\mathrm{BSc}$ and MSc from Eindhoven University of Technology in 1985 and 1989 respectively. Prior to 1996 he was at Eindhoven University of Technology and at UMIST, Manchester, UK. Math Bollen leads a team or researchers on power quality, reliability and power-electronic applications to power systems. His personal contribution to research consists of the development methods for voltage dip analysis, which resulted in a textbook on power quality. Math is active in IEEE, IEC and CIGRE working groups on voltage dip analysis and statistics. 